\title{
Renewed Challenge
}

by Rony Castro de Oliveira Lyrio*

Twenty-five years ago the Geneva Association was formed.

At that time, the world seemed bigger as political barriers and economical constraints characterized the living of individuals and organizations. The insurance industry and the reinsurance activities had to struggle with uncertainties not only connected with physical risks but also the ones derived from the financial barriers and controls which often were just formal but did jeopardize the development of the markets and did not contemplate the interests of the ultimate users.

During this last quarter of a century the role of the Geneva Association was fundamental in bridging the gap between old habits and new ideas. The discussions held among the associated members, the new concepts raised in the Geneva Papers brought the attention of the involved organizations to the transformations which were occurring.

The world now seems smaller as the free of the flow of ideas permits or forces creative solutions for crumbled down taboos.

The globalization of the economy and the continuous deregulation of the insurance industry have raised new challenges to cover the larger risks created by a world which is smaller in communications and transfer of risks, but which is accumulating then at a speed and proportion nonimaginable a few years ago.

The blurring trend of the forces which make the insurance markets, - mainly the industrial side of risk and the financial aspects of larger masses of money requiring investments - is a new aspect of the economy which will need replies for questions not yet fully presented.

* President, Sul America Seguros, Brazil. 
A new ground also needs to be established for facing the good and bad sides of the globalization. The industry has to decide to what extent the joint economical forces will harm the not so giant organizations and which will be the space left for the domestic markets. Their essentiality is to be recognized and protected not only because they are necessary distribution systems but also because they constitute the instruments of identification of local needs which ultimately will be translated in risks to be covered.

Government should be out of the economy regulation, but the industry must come in and create the basis for an harmonious development in order that barriers and constraints do not ressuscitate.

This is one of the reasons why the importance of the Geneva Association is enlarged. The same way as it has helped the transition from old formulas to a new economical world, it is up to the Association to continue being the forum for discussions of confronting thoughts which will form the fundamentals of a reborn industry.

There is no doubt that the strength of the Geneva Association - the exchanging of new ideas - is up to the revigorated challenge and that the Association will significantly help to solve the riddle. 